This item was submitted to Loughborough's Research Repository by the author.

Items in Figshare are protected by copyright, with all rights reserved, unless otherwise indicated.

\title{
Optimising curvature of carbon fibre-reinforced polymer composite panel for improved blast resistance: finite-element analysis
}

\section{PLEASE CITE THE PUBLISHED VERSION}

http://dx.doi.org/10.1016/j.matdes.2014.01.034

PUBLISHER

(C) Elsevier

VERSION

AM (Accepted Manuscript)

\section{LICENCE}

CC BY-NC-ND 4.0

\section{REPOSITORY RECORD}

Phadnis, Vaibhav A., Puneet Kumar, Arun Shukla, Anish Roy, and Vadim Silberschmidt. 2014. "Optimising Curvature of Carbon Fibre-reinforced Polymer Composite Panel for Improved Blast Resistance: Finite-element Analysis". figshare. https://hdl.handle.net/2134/14231. 
This item was submitted to Loughborough's Institutional Repository (https://dspace.lboro.ac.uk/) by the author and is made available under the following Creative Commons Licence conditions.

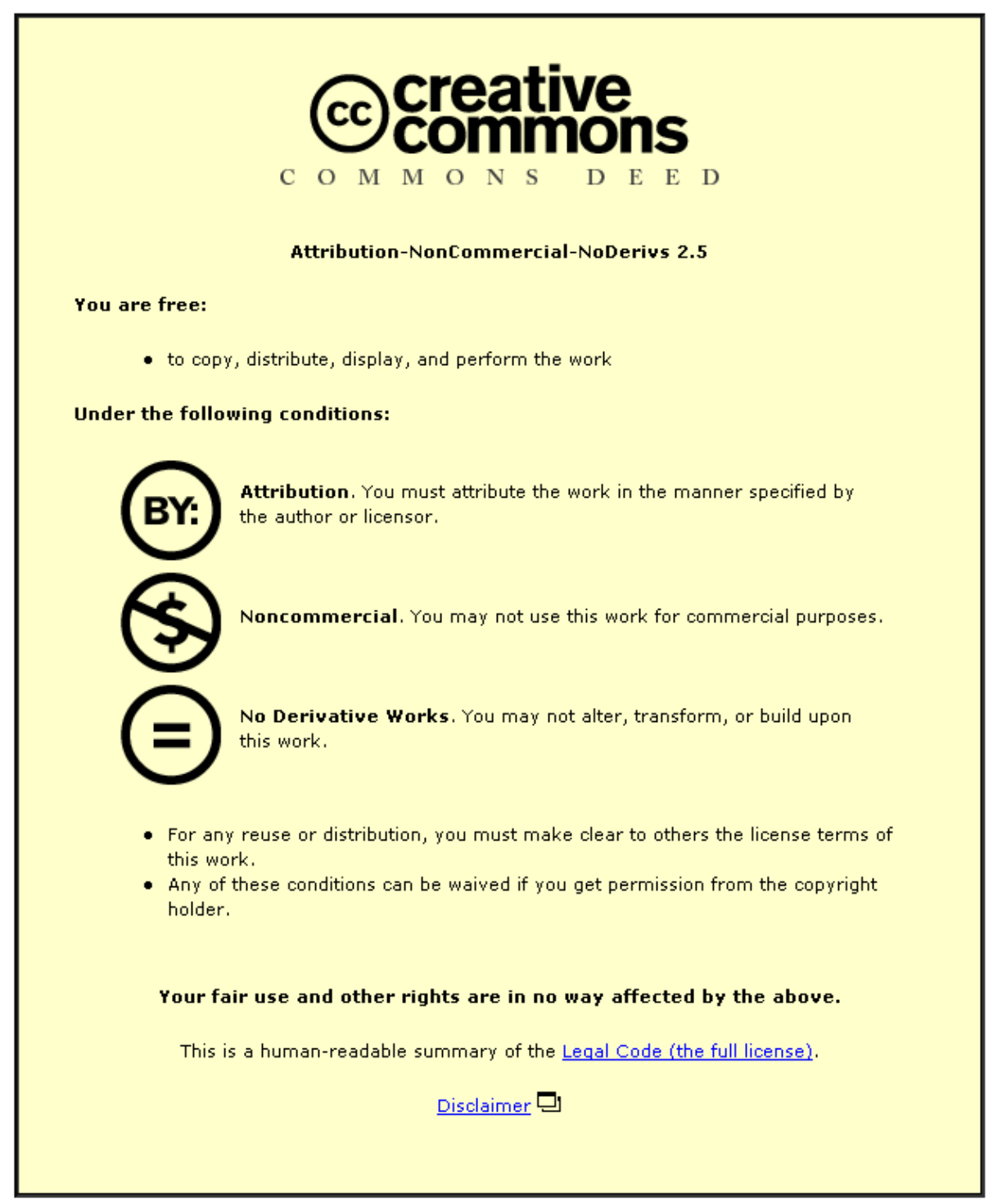

For the full text of this licence, please go to: http://creativecommons.org/licenses/by-nc-nd/2.5/ 


\title{
Optimising curvature of carbon fibre-reinforced polymer composite
}

\section{panel for improved blast resistance: Finite-element analysis}

\author{
Vaibhav A. Phadnis ${ }^{1}$, Puneet Kumar ${ }^{2}$, Arun Shukla $^{2}$, Anish Roy ${ }^{1}$, Vadim V. Silberschmidt ${ }^{1, *}$ \\ ${ }^{1}$ Wolfson School of Mechanical and Manufacturing Engineering, Loughborough University, LE11 \\ 3TU, UK \\ ${ }^{2}$ Dynamic Photomechanics Laboratory, Department of Mechanical Engineering and Applied \\ Mechanics, University of Rhode Island, Kingston, RI, USA \\ 1,*'Corresponding author: Vadim V. Silberschmidt, Tel: +44 (0) 1509227504, \\ Email:v.silberschmidt@lboro.ac.uk
}

\begin{abstract}
Numerical studies were conducted to investigate the optimum curvature of a carbon fibrereinforced polymer (CFRP) panel that would provide an improved blast resistance. A dynamic finite-element (FE) model that incorporates fluid-structure interaction was developed to evaluate the response of these panels to blast in commercial finite-element software ABAQUS/Explicit. Previously reported experimental data by authors were utilised to validate a FE model, where a shock-tube apparatus was utilized to apply a controlled shock loading to quasi-isotropic composite panels with different radii of curvature. A threedimensional digital image correlation (DIC) technique coupled with high-speed photography was employed to measure out-of-plane deflections and velocities, as well as in-plane strains at the back face of panels. Macroscopic post-mortem analysis was performed to compare the deformation in these panels. The numerical results were compared to the experimental data and demonstrated a good agreement. The validated FE model was further used to predict the optimal curvature of CFRP panel with the aim to improve its blast-mitigation characteristics.
\end{abstract} Keywords: Blast, Carbon fibre-reinforced composite panel, Curvature, Dynamic fracture, Finite-element analysis, Optimisation 


\section{Introduction}

Controlled and accidental explosions or detonations cause high-intensity dynamic loading on structures in the immediate vicinity of the event. Thus, it becomes crucial to assess critically the blast resistance of structures, which may not have been designed to resist explosions, such as important civilian as well as governmental and defence buildings and structures.

In recent years, a potential application of fibre-reinforced polymer (FRP) composites, especially CFRP laminates, in building structures with blast resisting properties has drawn the attention of the research community. CFRP composites are widely used in protective structural applications, often retrofitted to existing structures to improve its resistance to blast. This is primarily due to their excellent mechanical properties such as high strength-toweight ratio, durability and high impact resistance.

Composite structures are not limited to flat geometries; there are various applications requiring curved shapes, for instance, shells in a submarine hull [1, 2]. The effect of curvature of these structures on their blast-mitigation properties has been the subject of interest of various studies, with most relevant works [1, 3-5]. Rajendran and Lee [6] conducted a detailed review of phenomena related to air explosions and their effect on plane plates. They found that the peak overpressure and impulse generated during the blast were the most important parameters that affected the mechanical behaviour of these plates. Tekalur et al. [7] analysed the effect of different fibres reinforcing epoxy-based composite panels on their blast response. They used two different fibre materials: E-glass and carbon, and exposed the composite panels to high strain rates and quasi-static loading. Under dynamic loading, the carbon-fibre composites showed catastrophic failure, while E-glass-fibre composites exhibited a progressive damage behaviour. Arora et al. [3] studied a blast response of glassfibre sandwich composite panels fixed at their edges and exposed to blasts caused by real explosives at varying stand-off distances. They used high-speed photography and digital 
image-correlation (DIC) analysis to characterise the blast response of the studied panels. Damage was observed to initiate in the form of a crack in the front skin, leading to localised delamination around the cracked region and shear-induced failure at the core. Interfacial failure between the front skin and the core was also observed. This analysis also employed a finite-element study to verify experimental observations such as transient boundary conditions.

Recently, Kumar et al. [5] reported in their study the effect of transient boundary conditions, where the dynamic response of curved CFRP panels was analysed using high-speed photography and a 3D DIC technique followed by a post-mortem analysis. They found that curvature had a profound effect on the blast response of the CFRP panels. Ochola et al. [8] reported on strain-rate sensitivity of CFRP and glass-fibre-reinforced polymer (GFRP) composites by testing a single-laminate configuration with a strain-rate varying from $10^{-3} \mathrm{~s}^{-1}$ to $450 \mathrm{~s}^{-1}$. The results showed that dynamic strength of GFRP increased with the growing strain rate while the strain to failure for both CFRP and GFRP decreased. LeBlanc and Shukla [1] analysed the blast response of curved composite panels with the aim to study the energy distribution during this event. In general, blast experiments are rather complex to carry out and analyse due to difficulty in obtaining reliable output data. Hence, a robust and reliable numerical model can potentially be a valuable tool in design of structures with improved blast resistance.

In this paper, a dynamic response of CFRP panels with quasi-isotropic properties and three different radii of curvature to blast loading is studied numerically. A finite-element (FE) model of blast-loading response of CFRP panels was developed in ABAQUS 6.11 and its results were compared to experimental findings reported in [5]. A shock tube was employed to apply a blast load to the panels. The out-of-plane deflection, velocity and in-plain strain at 
the back face of these panels were used as bases for validation of FE model. The FE model was then utilised to suggest the optimal panel curvature to improve its blast resistance.

\section{Experimental procedure}

\subsection{Material and specimen}

Panels with three different radii of curvature (Fig. 1) were utilized in the experiments: infinite (i.e. flat; Panel A), $304.8 \mathrm{~mm}$ (Panel B) and $111.8 \mathrm{~mm}$ (Panel C). The specimens were fabricated using unidirectional AS4/3501-6 prepreg (fibre volume-fraction of 60\%) manufactured by the Hercules Corporation of Magna, Utah. The stacking sequence of this composite laminate $-\left[0^{0} / 90^{0} /+45^{0} /-45^{0}\right]_{4 \mathrm{~s}}$ with 32 layers of unidirectional plies - was selected to have quasi-isotropic effective properties; the specimens were $203 \mathrm{~mm} \times 203 \mathrm{~mm} \times 2 \mathrm{~mm}$ in size. For the curved panels, arc lengths of the curved edges correspond to the plate length of $203 \mathrm{~mm}$. The material properties of the studied laminate are listed in Table 1.

\subsection{Shock loading apparatus and loading conditions}

In experiments, a blast load can be imposed onto a structure using two different methods either by the controlled detonation of explosives or with the use of shock tubes. The use of explosives is dangerous and produces spherical wave fronts and pressure signatures, which are spatially complex and difficult to measure. On the contrary, a shock-tube offers the advantage of planar wave fronts so that the wave parameters may be easily controlled. Furthermore, the loading conditions are easier to replicate in finite-element simulations. Thus, the shock-tube apparatus was the preferred choice in the application of the blast load in our experiments. The apparatus used in this study and locations of pressure transducers, recording pressure history of incident and reflected wave, are shown in Figs. 1b and c respectively. Details about the shock-tube apparatus employed in the experiments and pressure-profiles obtained for studied CFRP panels can be found in the Kumar et al. [5]. 


\section{Finite-element model}

A numerical simulation of deformation and damage processes in composite panels is a valuable tool, as it would significantly curtail the need to conduct expensive and laborious experiments on life-sized specimen. Regarding this, a dynamic FE model of blast loading and response of curved carbon/epoxy panels was developed in the general-purpose finite-element software package ABAQUS/Explicit [11]. Details of the finite element modelling strategy, including the material modelling procedure are discussed next.

\subsection{Material model}

A user-defined damage model (VUMAT) with 3D continuum elements was developed and implemented to predict the damage characteristics through the laminate's thickness under the blast load. The model is able to characterise damage in a composite laminate by employing a stiffness-degradation concept with the help of an element-deletion approach based on the initiation and evolution of damage in the meshed domain [12]. Another damage mode interply delamination - is simulated using cohesive elements inserted between the adjacent plies of the laminate. The general-contact algorithm in ABAQUS/Explicit was used to model the contact conditions between the shock wave and the composite laminate, and between the laminae by defining appropriate contact-pair properties. The results of numerical simulations were evaluated using comparison with the experimental data.

\subsubsection{Damage initiation}

Damage modelling in composites at a laminate level typically requires input of several parameters, including homogenised ply properties, interply strength and information about the laminate's lay-up. Here, we adopt a layer-by-layer modelling strategy to capture failure in each ply [12]. This offers several advantages. First, full 3D stress states can be analysed. Typically, FE models of deformation in composites involve the use of 2D shell element to represent composite plies; this does not allow for accurate representation of stresses through 
the composite's thickness. Secondly, intraply and interply damage can be introduced discretely along with phenomenological models that account for the complex interaction between them.

To model damage initiation and propagation in the composite laminate, we employ the element-removal scheme in ABAQUS/Explicit, i.e. a finite-element was removed from the mesh as the threshold level, primarily in the fibre direction, was attained by the instantaneous stress in this element. A combined approach employing advantages of both linear-elastic fracture mechanics (LEFM) and damage mechanics used for delamination modelling is also discussed in this section. Many criteria are available for modelling damage in fibre-reinforced polymer composites that have their advantages and shortcomings. For example, Hashin's criteria [13] possess the capability to differentiate between discrete damage modes of fibre and polymer matrix material employing merely six input parameters that include ply strengths, stiffnesses and Poisson's ratio. Hence, it has been extensively used in industry for years thanks to its simplicity; still, some studies indicate that it is limited in predicting damage in a brittle polymer matrix with acceptable accuracy [14-15]. In this regard, the Puck's criterion [16] was shown to provide a reasonably good estimate of damage in epoxy matrix both qualitatively and quantitatively; an extensive review is available in [14-15]. In our FE model, a combination of the Hashin's [13] and Puck's [16] failure criteria is used to employ advantages of the both schemes. The Hashin's criteria are used to estimate damage in carbon fibres while damage in epoxy matrix is modelled using the Puck's criteria. The empirical formulation of these criteria has the following form:

Hashin's criteria for failure in fibres:

Fibre tensile failure $\left(\sigma_{11} \geq 0\right)$

$$
\left(\frac{\sigma_{11}}{X_{1 t}}\right)^{2}+\left(\frac{\sigma_{11}}{S_{12}}\right)^{2}+\left(\frac{\sigma_{11}}{S_{13}}\right)^{2}=1, d_{f t}=1
$$


Fibre compressive failure $\left(\sigma_{11}<0\right)$

$$
\left(\frac{\sigma_{11}}{X_{1 c}}\right)^{2}=1, d_{f c}=1
$$

Puck's criteria for failure in epoxy matrix:

Matrix failure

$$
\begin{aligned}
& {\left[\left(\frac{\sigma_{11}}{2 X_{1 t}}\right)^{2}+\frac{\left(\sigma_{22}\right)^{2}}{\left|X_{2 t} \cdot X_{2 c}\right|}+\left(\frac{\sigma_{12}}{S_{12}}\right)^{2}\right]+\sigma_{22}\left(\frac{1}{X_{2 t}}+\frac{1}{X_{2 c}}\right)=1 .} \\
& \sigma_{22}+\sigma_{33}>0, d_{m t}=1 \\
& \sigma_{22}+\sigma_{33}<0, d_{m c}=1
\end{aligned}
$$

Here $\sigma_{11}, \sigma_{22}, \sigma_{33}$ and $\sigma_{12}$ are the components of stress tensor at an integration point of an element; $d_{f t}, d_{f c}, d_{m t}$ and $d_{m c}$ are the damage variables associated with failure modes in fibre tension, fibre compression, matrix tension and matrix compression, respectively. $X_{1 t}, X_{2 t}$ and $X_{2 c}$ are tensile failure stress in the fibre direction, tensile failure and compressive failure stress in the transverse, respectively, while $S_{11}, S_{12}$ and $S_{13}$ are shear failure stresses in 1-2, 2-3 and 1-3 planes, respectively. The mechanical properties of a CFRP laminate used in this FE analysis are listed in Table 1. The Puck's formulation was suitably modified to include the strain-rate-dependence of epoxy matrix at high strain rates that are observed in blast events. These modified equations (Eqs. (4-5)) were then implemented in a user-defined material model (VUMAT) in ABAQUS/Explicit.

\subsubsection{Modelling rate-dependency}

The polymer matrix material in a CFRP composite demonstrates strain-rate-sensitivity at high strain rates $\left(\sim 10^{3} \mathrm{~s}^{-1}\right)$, which are typical for a blast event. This effect becomes significant, particularly for transverse directions, in cases where polymer matrix is the primary loadbearing member [18-22]. Many test methods have been developed to facilitate the dynamic characterisation of composite materials at high deformation rates. Previous test studies 
highlighted the increase in stiffness and strength of composites with an increasing strain rate in matrix-dominated regions [17-21]. In some cases, explicit empirical relations were formulated to derive such material properties at corresponding strain-rates [20-21]. The composite laminate used in our experiments - AS4/3501-6 - was shown to exhibit a strain-hardening behaviour at high loading rates [21]. The response of AS4/3501-6 laminate at various biaxial stress states e.g. combined transverse compression and shear, at strain rates varying from $10^{-4} \mathrm{~s}^{-1}$ to $400 \mathrm{~s}^{-1}$ was characterised. Stress-strain data at failure, initial moduli, and strength were also recorded. Empirical relationships between the matrix-dominated properties and strain rates under high-strain rate deformation were as follows:

- for in-plane shear and transverse moduli:

$$
\begin{aligned}
& E(\dot{\varepsilon})=E\left(\dot{\varepsilon}_{0}\right)\left[m_{e} \log \left(\frac{\dot{\varepsilon}}{\dot{\varepsilon}_{0}}\right)+1\right] . \\
& m_{e}=0.045, \dot{\varepsilon}_{0}=10^{-4} \mathrm{~s}^{-1}
\end{aligned}
$$

- for in-plane shear and transverse strength:

$$
\begin{aligned}
& F(\dot{\varepsilon})=F\left(\dot{\varepsilon}_{0}\right)\left[m_{f} \log \left(\frac{\dot{\varepsilon}}{\dot{\varepsilon}_{0}}\right)+1\right] . \\
& m_{f}=0.057, \dot{\varepsilon}_{0}=10^{-4} \mathrm{~s}^{-1}
\end{aligned}
$$

Here, $E(\dot{\varepsilon})$ and $F(\dot{\varepsilon})$ are the instantaneous in-plane moduli of elasticity and shear strength at a strain-rate of $\dot{\varepsilon}$, respectively, $\dot{\varepsilon}_{0}=10^{-4} \mathrm{~s}^{-1}$ is the reference strain-rate, which corresponds to quasi-static loading, while $m_{e}=0.045$ and $m_{f}=0.057$ are curve-fitting parameters. Eqs. (4)(5) form the basis of the dynamic material properties used in our simulations.

The average maximum strain rates for the studied composite panels under blast loading were analysed, initially without specifying strain-rate-dependent properties, with our FE simulations. They were observed to be in the range of $2200 \mathrm{~s}^{-1}$ to $2400 \mathrm{~s}^{-1}$ for panel A, $3500 \mathrm{~s}^{-1}$ to $3800 \mathrm{~s}^{-1}$ for panel B and, $1500 \mathrm{~s}^{-1}$ to $1800 \mathrm{~s}^{-1}$ for panel C. The matrix-dominated properties reported by Daniel et al. [21] for a similar composite were suitably extrapolated to 
match these strain rates (Table 1) and incorporated in the failure criteria of our simulations. For this, Eqs. (1) and (3) were modified as

$$
\begin{aligned}
& \left(\frac{\sigma_{11}}{S_{11}}\right)^{2}+\left(\frac{\sigma_{11}}{S_{12}{ }^{*}(\dot{\varepsilon})}\right)^{2}+\left(\frac{\sigma_{11}}{S_{13}{ }^{*}(\dot{\varepsilon})}\right)^{2}=1, d_{f t}=1 \\
& {\left[\left(\frac{\sigma_{11}}{2 X_{1 t}}\right)^{2}+\frac{\left(\sigma_{22}\right)^{2}}{\left|X_{2 t}{ }^{*}(\dot{\varepsilon}) \cdot X_{2 c}{ }^{*}(\dot{\varepsilon})\right|}+\left(\frac{\sigma_{12}}{S_{12}{ }^{*}(\dot{\varepsilon})}\right)^{2}\right]+\sigma_{22}\left(\frac{1}{X_{2 t}{ }^{*}(\dot{\varepsilon})}+\frac{1}{X_{2 c}{ }^{*}(\dot{\varepsilon})}\right)=1} \\
& \sigma_{22}+\sigma_{33}>0, d_{m t}=1 \\
& \sigma_{22}+\sigma_{33}<0, d_{m c}=1,
\end{aligned}
$$

where $S_{12}{ }^{*}(\dot{\varepsilon})$ and $S_{13}{ }^{*}(\dot{\varepsilon})$ are dynamic shear strengths in transverse directions (1-2 and 1-3), while $X_{2 t}{ }^{*}(\dot{\varepsilon})$ and $X_{2 c}{ }^{*}(\dot{\varepsilon})$ are dynamic tension and compression strengths in transverse direction at respective strain rates for the studied composite panels. The element-deletion approach used to remove the elements from the mesh was based on the magnitude of damage variables as calculated with Eqs. (2), (6)-(7), applied to discrete damage modes in the modelled CFRP composite. The element was removed when the maximum damage condition was satisfied at an integration point of an element. The damage parameter, $d \in \max \left(d_{f t}, d_{f c}, d_{m t}, d_{m c}\right)$, based on the above formulations was calculated so that when $d=1$ (at integration point of an element) the element was removed from the mesh, and it offered no subsequent resistance to deformation.

\subsubsection{Delamination modelling}

Delamination at the interface of neighbouring plies of a laminate was modelled using cohesive-zone elements (CZEs) available in ABAQUS/Explicit. The elastic response of such an interface was modelled using stiffness of CZEs, calculated with an empirical formula suggested by Turon et al. [22]. Delamination initiation was modelled using a bilinear traction-separation law with a quadratic nominal-stress criterion [12], while its post-damage response was calculated using a power law $[12,22]$ that accounted for mode-mixity. Detailed 
description of this can be found in [12]. The mechanical properties of cohesive elements used in our simulations are listed in Table 1.

\section{2 $\quad$ FE model and boundary conditions}

The 3D finite-element model developed in ABAQUS 6.11 [11] consisted of a shock-tube wall and a CFRP panel. The shock tube was modelled with shell elements with five integration points through its thickness. The elements of the wall had an edge length of $2 \mathrm{~mm}$ and shell thickness of $25.4 \mathrm{~mm}$. The CFRP panels were modelled as a solid continuum with mechanical properties listed in Table 1 . These panels were meshed with eight-node, oneintegration-point hexahedral elements C3D8R with an element size of $1 \mathrm{~mm}$ along the length, while each ply was assigned one element though its thickness. There were a total of 1.7 million elements in this structural domain. The material co-ordinate system was assigned to the panel such that it captured a discrete orientation of each element accurately following the curvature. The schematic for meshed CFRP panel C is shown in Fig. 2. The boundary conditions employed in this model reflected the physical constraints applied in the experiments. All edges of the panels were fully constrained. All the degrees of freedom at the shock tube wall were also fully constrained, since it was considered rigid in our simulations. All three panels in our simulations were positioned against the wall of the shock tube as shown in Fig. 3.

\subsection{Fluid-structure coupling and shock-wave loading}

The fluid model consisted of the air inside and outside the shock tube as well as the air surrounding the plate as shown in Fig. 2a. The air outside the tube was modelled in an Eulerian domain as a cuboid with a domain size of $400 \mathrm{~mm} \times 400 \mathrm{~mm}$ in X-Y plane and 2000 $\mathrm{mm}$ along the tube axis. The model had $100 \mathrm{~mm}$ of air along the tube axis behind the plate to ensure that the plate remained in air during deformation caused by shock-wave loading. The air inside the tube was also modelled in the Eulerian domain with the element size of $3 \mathrm{~mm}$. 
All the fluid elements were meshed with the Eulerian eight-node, one-integration-point hexahedral elements EC3D8R. The acoustic structural coupling between acoustic pressure of the fluid mesh and structural displacements of the CFRP panel was accomplished with a surface-based tie constraint at the common surface. The master-slave type of contact was established between the annular surface of the shock tube in contact with the CFRP panel and the top surface of the panel. The surface of the external fluid at the interface was designated as the master surface. The incident wavefront was assumed to be planar. For a planar wave, two reference points, namely, the standoff point and the source point were defined (Fig. 2a). The relative positions of these two reference points were used to determine the direction of travel for the incident shock wave; the pressure history at the standoff point was used to drive it. The 'amplitude' definition in ABAQUS/Explicit [11] was employed to specify the shock load on the front surface of the CFRP panel using the pressure-history data. The entire analysis was divided into two steps pertaining to the wave incidence and reflection, with appropriate magnitudes of average shock-wave velocity and density were used. Linear fluid mechanics was used for the entire model. The observed total pressure in the fluid was divided into two components: the incidents wave itself, which was known, and a calculated wave field in the fluid due to reflections at the fluid boundaries and interactions with the solid.

\section{Results and discussion}

The results obtained in this numerical study are discussed below. The FE analysis was employed to compute the out-of-plane deflections of CFRP panels at the centre of their rear faces, energy distributions during blast, and damage in the panels. A parametric study was carried out to suggest the optimal curvature of CFRP panel for improved blast resistance.

\subsection{FE model validation}

The FE model allows for the observation of interaction of shock front with the CFRP panels and their deformation under shock loading. The deflection, velocity and strain data acquired 
using the DIC technique $[4,5]$ was used as a basis to validate the FE model. Initially, the flat panel (Panel A) had a uniform deflection within a central region of loading. This out-of-plane deflection decayed gradually towards the edges. When the radius of curvature was increased, the effective loading area changed its shape from circular to elliptical. For the curved panels, shock loading primarily acted upon the projected area unlike the circular area as in case of flat panel, which caused this change in a shape. During the early stages of shock loading, contours of out-of-plane deflection were not affected by the boundary conditions. Deflection of Panel A started as a circular region, which continued until $150 \mu \mathrm{s}$. This was a localized circular deflection contour, which had roughly the same diameter as that of the muzzle (at $\mathrm{t}=$ $50 \mu \mathrm{s})$. At $\mathrm{t}=150 \mu \mathrm{s}$, the boundary conditions started to affect the development of deflection contours in the panel. The stress waves generated in the specimen travelled outwards and were reflected by the boundary. This reflected stress wave caused the change in the shape of the deflection contours. The full-field deflection at the failure loading for these panels can be found in [5].

\subsection{Modes of deflection in CFRP panels}

The FE analysis demonstrated that deflection of the studied CFRP panels was the combined result of two deflection modes, namely, the indentation mode and the flexure mode. It was seen that all the panels started deflecting in the indentation mode initially. In the flat panel (Panel A), the global flexural mode quickly began dominating the deflection process. This was confirmed by the continuous nature of displacement contours that show a monotonic increase in deflection from the edge to the centre of the specimen after $t=200 \mu$ s. Deflection of Panel B continued in the indentation mode up to about $400 \mu \mathrm{s}$, after which it changed to the global flexural deflection mode. These deflection contours show a continuous increase in deflection from the edge to the centre of panel and the transition from elliptical contours back to the circular shape. In Panel C, the deflection was observed to be less than that in Panels A 
and B since only the central loading region was affected. In addition to the out-of-plane deflection, velocities and in-plane strain data were also extracted from FE model at the centre point of the back of the studied CFRP panels (Figs. 4 a-c). Figure 4 a shows that the deflection rate $(35 \mathrm{~m} / \mathrm{s})$, for the initial $200 \mu \mathrm{s}$, was almost the same for all the three panels, though Panels A and B attained a higher deflection as compared to Panel C. This means that the Panel $\mathrm{C}$ was stiffer than the other two panels since it sustained a higher pressure and had a lower deflection. Panels A and B showed similar trends up to $1000 \mu \mathrm{s}$. At this time, damage was observed to initiate in Panel B, which explains the rapid increase in its deflection. The lower out-of-plane deflection (Fig. 4b) and in-plane strain (Fig. 4c) in Panel C showed that this panel had higher flexural rigidity. Panel B exhibited higher in-plane shear strain which led to its catastrophic failure.

\subsection{Damage in CFRP panels}

The observed variability of spatio-temporal evolution of deflections in the panels under blast load resulted in different realisation of damage modes. The damage development in Panel A at failure loading is shown in Fig. 5a. Apparently, fibre breakage was the dominant damage mode as observed from FE model and confirmed from [5]. The damaged regions were primarily located along the clamped edges, due to the constraints imposed, exposing the underlying fibres to the excessive tensile loading. The extent of damage was near about the same at clamped edges though varied along their thickness. In Panel B similar trend as was observed, though on a larger scale. Fibre breakage was the governing damage mode, though a large-scale delamination was also observed. Damage initiated in the form of fibre breakage at the clamped boundaries and propagated towards the mid-region, where Panel B failed (Fig. 5b). The damage in Panel $\mathrm{C}$ at threshold loading is shown in Fig. 5c, where no fibre breakage or delamination was observed. Using the developed FE model, this panel was then exposed to a higher pressure of $8 \mathrm{MPa}$, where it failed catastrophically at around $1000 \mu \mathrm{s}$, following the 
similar damage trend as observed in Panel B. The deflection, and in-plane strain data at the centre point of the Panel $\mathrm{C}$ at this load (8 MPa) is shown in Fig. 6.

\subsection{Energy distribution during blast}

The incident and remaining energies associated with the shock loading intensities were analysed with the developed FE models. The energy lost was obtained by subtracting the remaining energy from the incident energy. The magnitudes of energies (incident, remaining, and lost) for all the three loading cases are shown in Fig. 7. Panel $\mathrm{C}$ was subjected to the highest intensity of shock loading and so the incident energy was the highest for this panel. The energy remaining in the gas is identical with impact energy as this is the actual energy that the panel experienced due to shock loading. Since Panel C reflected a major part of the incident shock energy, it was exposed to lower impact energy while Panel B was subjected to the highest impact energy. The ratio of impact energy (remaining energy in the gas) to the incident energy was considered as an indication of the blast mitigation ability of studied CFRP panels. Panel $\mathrm{C}$ had the lowest ratio of impact to incident energy, which indicates its enhanced blast mitigation capacity. Consequently, Panel B with the highest ratio demonstrates its poor blast mitigation capacity. To clarify, energy evolution analysis for all three panels was performed at the same loading pressure. The panels had different levels of energy dissipation capacities. Again, Panel $\mathrm{C}$ had the lowest ratio of impact to incident shock energy whereas the Panel B had the highest.

\subsection{Parametric study and predictions}

The developed numerical model was utilised to investigate the optimum curvature of the CFRP panel that would result in better blast-mitigation properties. The incident shock energy was maintained as before for comparability. Since Panel C outperformed the other two as discussed in Section 4.4, it was considered as a basis for the optimisation. Here CFRP panels with radii of curvature varying between $105 \mathrm{~mm}$ to $76 \mathrm{~mm}$ (105 mm, $100 \mathrm{~mm}, 90 \mathrm{~mm}, 87$ 
$\mathrm{mm}, 80 \mathrm{~mm}$ and $76 \mathrm{~mm}$ ) were simulated. It was observed that, as the radius of curvature of the CFRP panel was reduced (from $110 \mathrm{~mm}$ to $76 \mathrm{~mm}$ ); the shock wave glided over the exposed surface, and almost no noticeable out-of plane deflection was observed. In case of CFRP panel with the radius of curvature of $76 \mathrm{~mm}$ (Panel D), the major portion of shock energy was reflected by the panel towards the shock-tube wall and partially vented outside the fluid-structure domain. Furthermore, the shock wave, reflected back from the shock-tube wall towards the CFRP panel, was reduced by the air surrounding the panel, and no significant out-of-plane deflection was observed. In this case, no damage was found on the exposed surface of, as well as within, the CFRP panel. The impact energy was noted to be as small as $30 \%$ of the incident energy. The pressure load was then gradually increased to 9.5 MPa (i.e. exceeding the failure level for Panel C) where the panel failed catastrophically due to fibre breakage. The critical blast pressure was about $19 \%$ higher than that responsible for failure in Panel C. The panels with radii of curvature below $76 \mathrm{~mm}$ were not simulated since their shape closely represents that of a closed cylinder where the application of appropriate boundary conditions could not be maintained. Also, the further reduction in the curvature would lead to the situation with the projected area of the shock tube spreading beyond the contour of the panels. The magnitude of maximum blast load sustained by the simulated panels just before their catastrophic failure is listed in Table 2.

\section{Conclusions}

The effect of curvature of composite panels on their blast-mitigation capacity was studied using a shock-tube apparatus. The performance of these panels under blast loading was characterised in terms of their out-of-plane deflection, in-plain stress and the damage and failure scenarios. A finite-element model was developed to simulate blast loading of curved CFRP panels and validated using the 3D DIC data coupled with high-speed photography. This model accurately accounted for the interaction between the shock wave, curved panels, 
shock tube and surrounding air. After validation, the FE model was employed to predict the optimum panel curvature that would demonstrate superior blast-mitigation properties using the envelope of parameters not covered by the experimental conditions. The following conclusions were drawn:

1) There were two main deformation modes contributing to deflection of the studied panels under shock loading: flexural and indentation. Flexural deformation decreased and indentation deformation increased as the radius of curvature was reduced. The indention mode was found to be more severe since it led to the damage initiation in the panels.

2) Fibre breakage was the dominant mode of damage observed in the studied panels at the failure loading as confirmed in [5] and was captured reasonably accurately with the developed FE model.

\section{Acknowledgement}

The authors at URI acknowledge the financial support provided by the Department of Homeland Security under Cooperative Agreement No. 2008-ST-061-ED0002 and the Office of Naval Research (Dr. Y.D.S. Rajapakse) under Grant No. N00014-10-1-0662.

\section{References}

[1] LeBlanc J, Shukla A. Dynamic response of curved composite panels to underwater explosive loading: experimental and computational comparisons. Compos Struct. 2011; 93: $3072-81$.

[2] LeBlanc J, Shukla A, Rousseau C, Bogdanovich A. Shock loading of three dimensional woven composite materials. Compos Struct. 2007; 79:344-55.

[3] Arora H, Hooper PA, Dear JP. Dynamic response of full-scale sandwich composite structure subject to air-blast loading. Compos Part A - Appl S. 2011; 42: 1651-1662. 
[4] Kumar P, LeBlanc J, Stargel DS, Shukla A. Effect of plate curvature on blast response of aluminium panels. Int J Impact Eng. 2012; 46: 74-85.

[5] Kumar P, Stargel DS, Shukla A. Effect of plate curvature on blast response of carbon composite panels. Compos Struct. 2013; 99(0):19-30.

[6] Rajendran R, Lee JM. Blast loaded plates. Mar Struct. 2009; 22: 99-127.

[7] Tekalur SA, Shivakumar K, Shukla A. Mechanical behaviour and damage evolution in Eglass vinyl ester and carbon composites subjected to static and blast loads. Compos Part B Eng. 2008; 39:57-65.

[8] Ochola RO, Marcus K, Nurick GN, Franz T. Mechanical behaviour of glass and carbon fibre reinforced composites at varying strain rates. Compos Struct. 2004; 63: 455467.

[9] Wang E, Shukla A. Analytical and experimental evaluation of energies during shock wave loading. Int Journal Impact Eng. 2010; 37:1188-96.

[10] Liu H, Gao ZK, Yao GC, You HJ, Zu GY. Performance of aluminium foam-steel panel sandwich composites subjected to blast loading. Mater Design. 2013; 47:483-8.

[11] Hibbitt, Karlsson \& Sorensen Inc., ABAQUS version 6.11; 2011.

[12] Phadnis V, Makhdum F, Roy A, Silberschmidt VV. Drilling in CFRP composites: Experimental investigations and finite element implementation. Compos Part A- Appl S. $2013 ; 47(0): 41-51$.

[13] Hashin Z. Analysis of stiffness reduction of cracked cross-ply laminates. Eng Fract Mech. 1986; 5: 771-8.

[14] Hinton MJ, Kaddour AS, Soden PD. A comparison of the predictive capabilities of current failure theories for composite laminates, judged against experimental evidence. Compos Sci Technol. 2002; 62(12-13):1725-97.

[15] Dandekar CR, Shin YC. Modelling of machining of composite materials: A review. Int J 
Mach Tool Manu. 2012; 57:102-21.

[16] Puck A, Schürmann H. Failure analysis of FRP laminates by means of physically based phenomenological models. Compos Sci Technol. 1998; 7: 1045-67.

[17] Naik NK, Rao KV, Veerraju C, Ravikumar G. Stress-strain behaviour of composites under high strain rate compression along thickness direction: Effect of loading condition. Mater Design. 2010. 31(1):396-401.

[18] Ochola RO, Marcus K, Nurick GN, Franz T. Mechanical behaviour of glass and carbon fibre reinforced composites at varying strain rates. Compos Struct. 2004; 63(3):455-467. [19] Raimondo L, Iannucci L, Robinson P, Curtis PT. Modelling of strain rate effects on matrix dominated elastic and failure properties of unidirectional fibre-reinforced polymermatrix composites. Compos Sci Technol. 2012; 72(7):819-827.

[20] Koerber H, Xavier J, Camanho P. High strain rate characterisation of unidirectional carbon-epoxy IM7-8552 in transverse compression and in-plane shear using digital image correlation. Mech Mater. 2010; 42(11):1004-1019.

[21] Daniel IM, Werner BT, Fenner JS. Strain-rate-dependent failure criteria for composites. Compos Sci Technol. 2011; 71(3):357-364.

[22] Turon A, Camanho PP, Costa J, Renart J. Accurate simulation of delamination growth under mixed-mode loading using cohesive elements: Definition of interlaminar strengths and elastic stiffness. Compos Struct. 2010; 92(8):1857-64. 


\section{Table captions}

Table 1 Mechanical properties of AS4/3501-6 UD composite laminate [5, 12, 21]

Table 2 Results of parametric study: Blast load sustained by panels before their failure

\section{Figure captions}

Figure 1 (a) Specimen geometry; (b) shock tube; (c) muzzle section showing locations of transduces [4-5]

Figure 2 (a) FE model setup; (b) boundary conditions, meshed CFRP Panel C and locations of cohesive zone elements (fibre orientation in a ply is shown with white dotted lines)

Figure 3 Orientation of specimens

Figure 4 Experimental and numerical results: (a) out-of-plane deflections; (b) out-of-plane velocities; (c) in-plain strain

Figure 5 Damage evolution in plates under blast loading: (a) fibre breakage in front face of Panel A at failure load; (b) Panel B at failure load; (c) Panel C at threshold load no global fracture is observed

Figure 6 Calculated response of Panel C at failure load: (a) deflection; (b) in-plain strain Figure 7 Energy-distribution in CFRP panels: Panel A and B (failure load), Panel C (threshold load) 
Table 1 Mechanical properties of AS4/3501-6 UD composite laminate [5, 12, 21]

Elastic moduli

Tensile strength in fibre direction, $X_{1 t}$

Compressive strength in fibre direction, $X_{1 c}$

Tensile strength in transverse direction, $X_{2 t}$

Compressive strength in transverse direction, $X_{2 c}$

Shear strength, $S$

Stiffness of cohesive zone, $K\left(\mathrm{~N} / \mathrm{mm}^{3}\right)$

Traction in normal direction, $\tau_{n}(\mathrm{MPa})$

Traction in shear -1 and 2 direction, $\tau_{s}=\tau_{t}(\mathrm{MPa}) \quad 86.88$

Mode - I fracture energy, $G_{I C}(\mathrm{~N} / \mathrm{mm})$

Mode II and III fracture energy, $G_{I I C}=G_{I I I C}(\mathrm{~N} / \mathrm{mm}) \quad 0.55$

Power law coefficient, $\beta$

Strain-rate dependent properties

Transverse modulus, $E_{2}(\mathrm{GPa})$

Shear modulus, $\mathrm{G}_{12}(\mathrm{GPa})$

Transverse tensile strength, $F_{2 t}(\mathrm{MPa})$

Transverse compressive strength, $F_{2 c}(\mathrm{MPa})$
$E_{x x}=147 \mathrm{GPa}, E_{y y}=11.2 \mathrm{GPa}, E_{x y}=7 \mathrm{GPa}$

$2004 \mathrm{MPa}$

$1197 \mathrm{MPa}$

$65 \mathrm{MPa}$

$285 \mathrm{MPa}$

$80 \mathrm{MPa}$

$5 \times 10^{6}$

53.78

0.08

1.8

\begin{tabular}{llllll}
\hline \multirow{2}{*}{ Strain-rate dependent properties } & \multicolumn{5}{c}{ Average strain - rates, $\dot{\varepsilon}\left(s^{-1}\right)$} \\
\cline { 2 - 6 } & 0.0001 & 1 & 400 & 2400 & 3800 \\
\cline { 2 - 6 } & 11.2 & 12.9 & 14.5 & {$[14.8]$} & {$[14.96]$} \\
Transverse modulus, $E_{2}(\mathrm{GPa})$ & 7 & 8.2 & 9 & {$[9.3]$} & {$[9.4]$} \\
Shear modulus, $\mathrm{G}_{12}(\mathrm{GPa})$ & 65 & 80 & 90 & {$[94]$} & {$[95]$} \\
Transverse tensile strength, $F_{2 t}(\mathrm{MPa})$ & 285 & 345 & 390 & {$[405]$} & {$[409]$} \\
Transverse compressive strength, $F_{2 c}(\mathrm{MPa})$ & & & & &
\end{tabular}

Note: Numbers in brackets denote extrapolated values. 
Table 2 Results of parametric study: Blast load sustained by panels before their failure 
Figure $1 \mathrm{a}$
Click here to download high resolution image
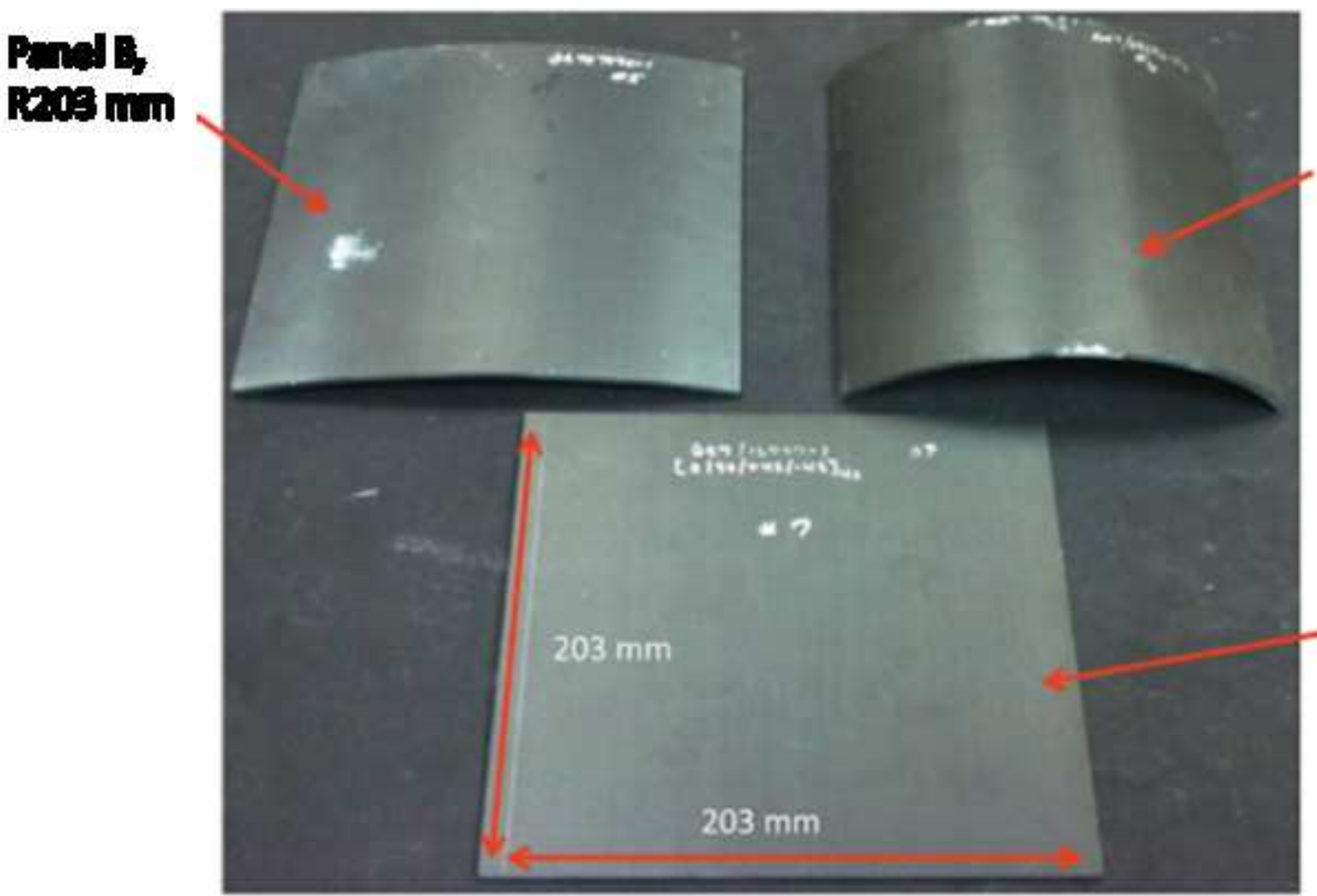

Pannelc

R412m

Pondila RS 
Click here to download high resolution image

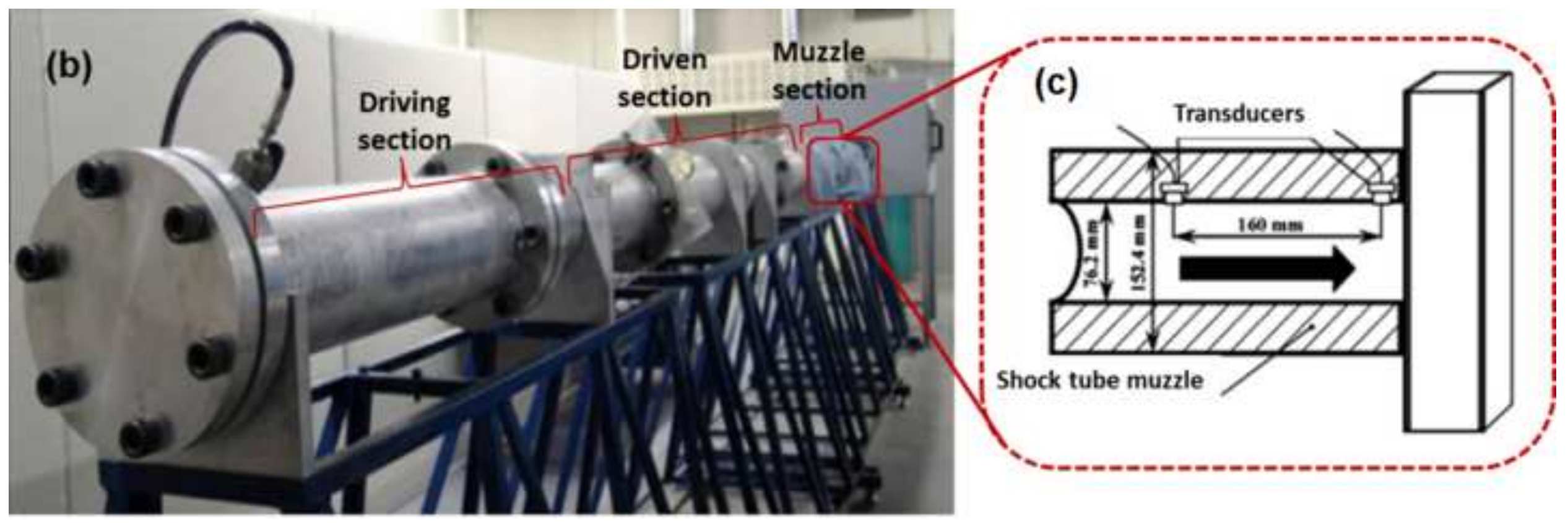




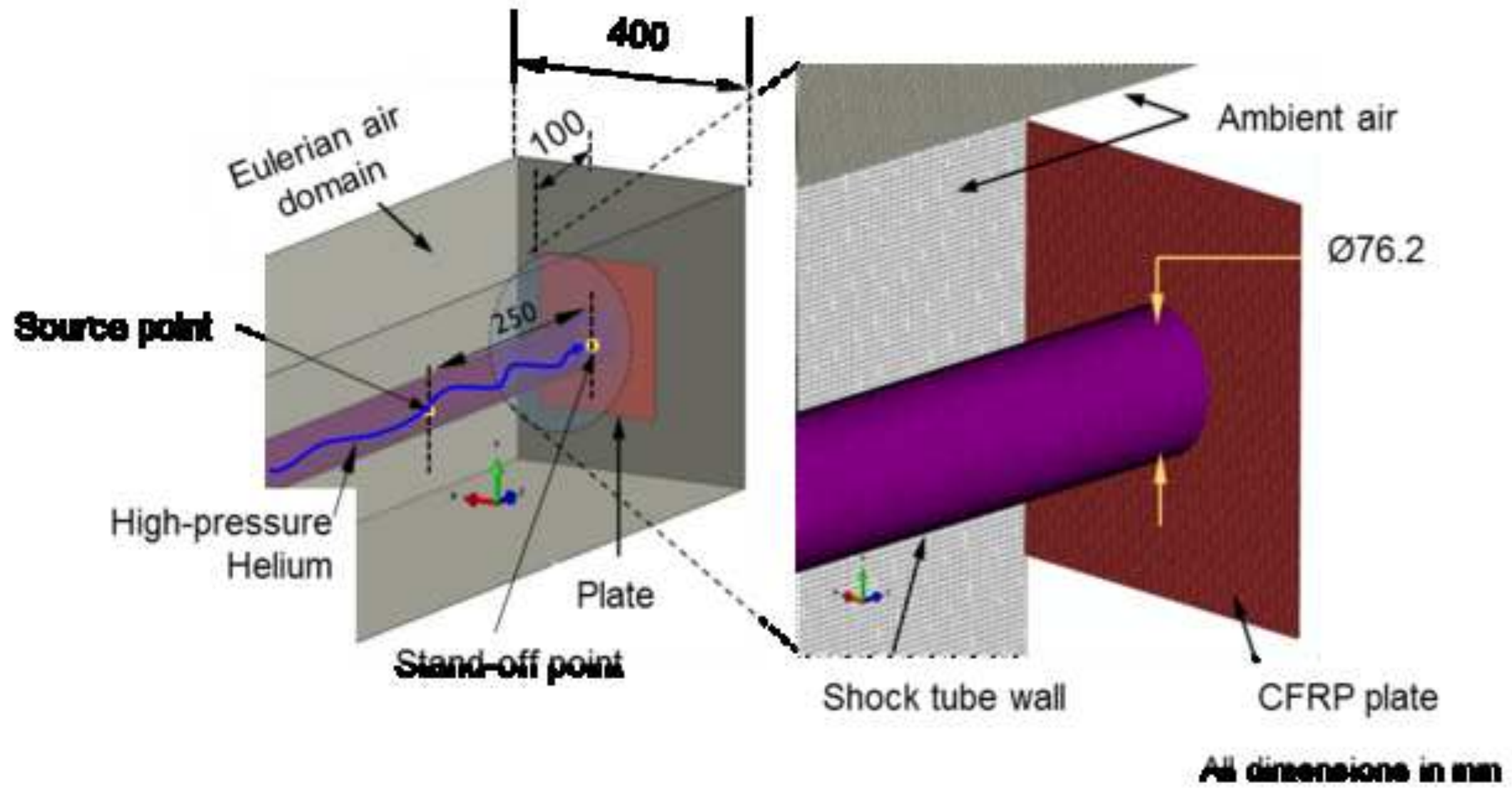




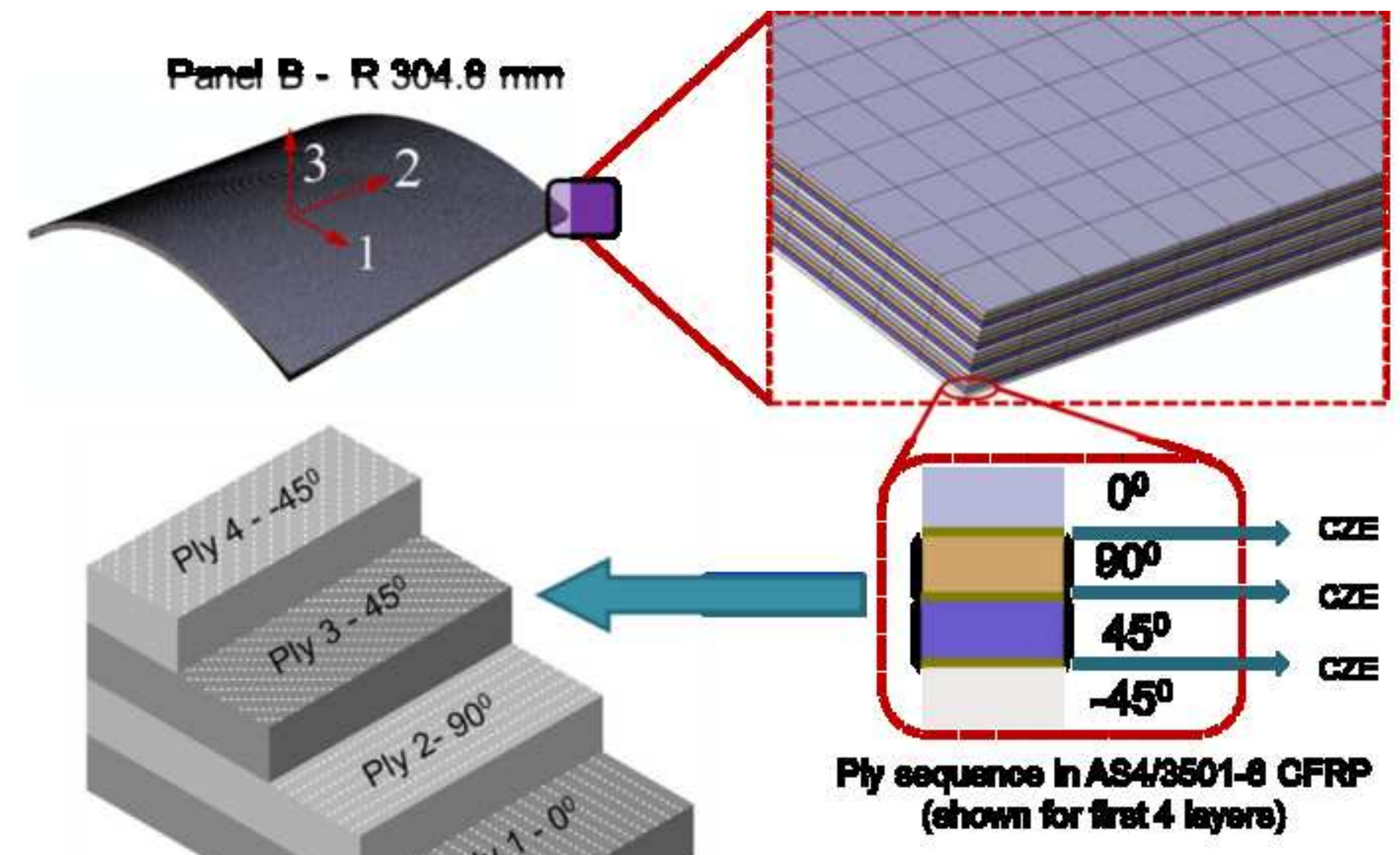

ply (chown for ifrt4 layere) 


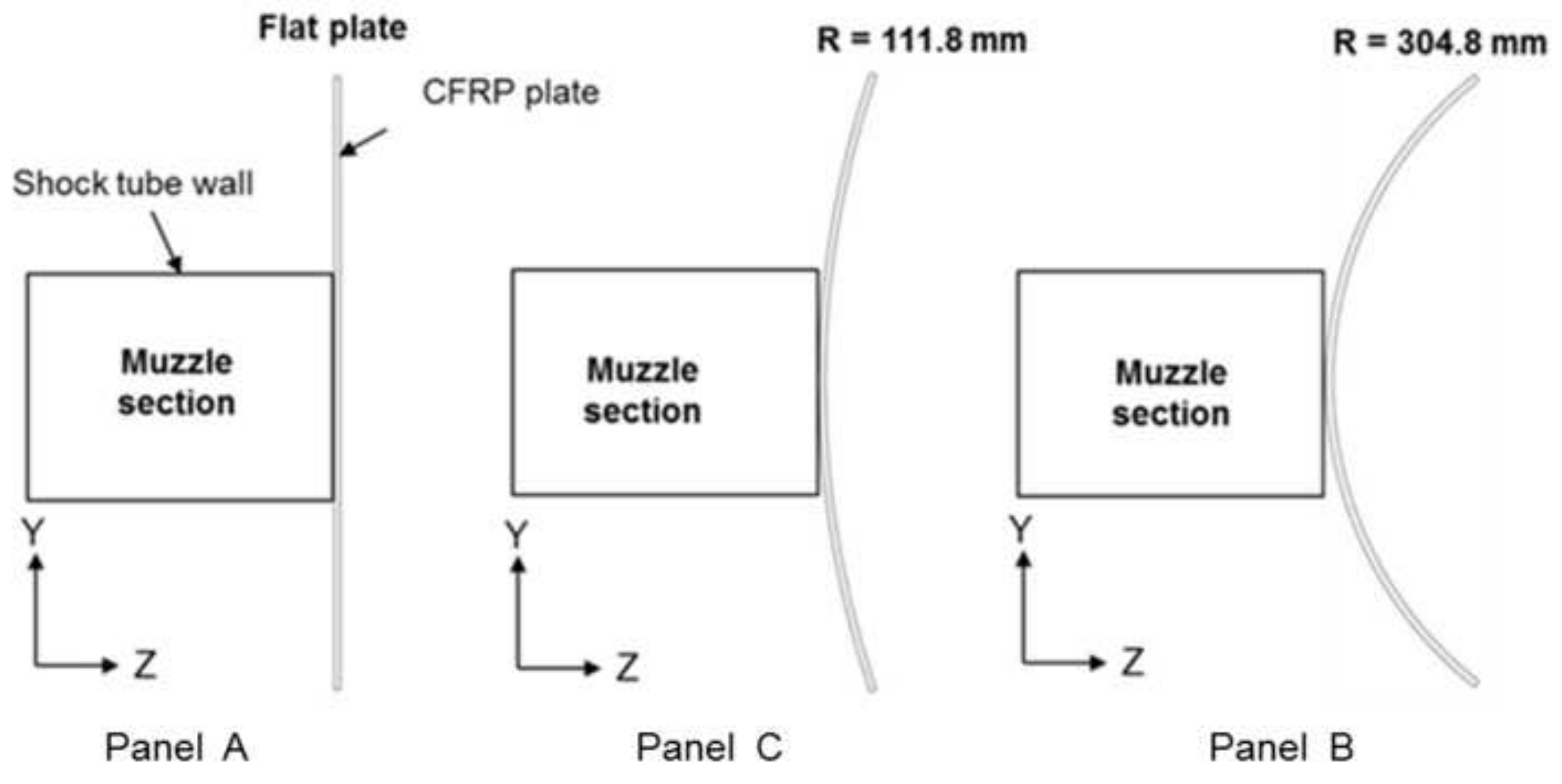

Note - All three panels are $2 \mathrm{~mm}$ thick. 


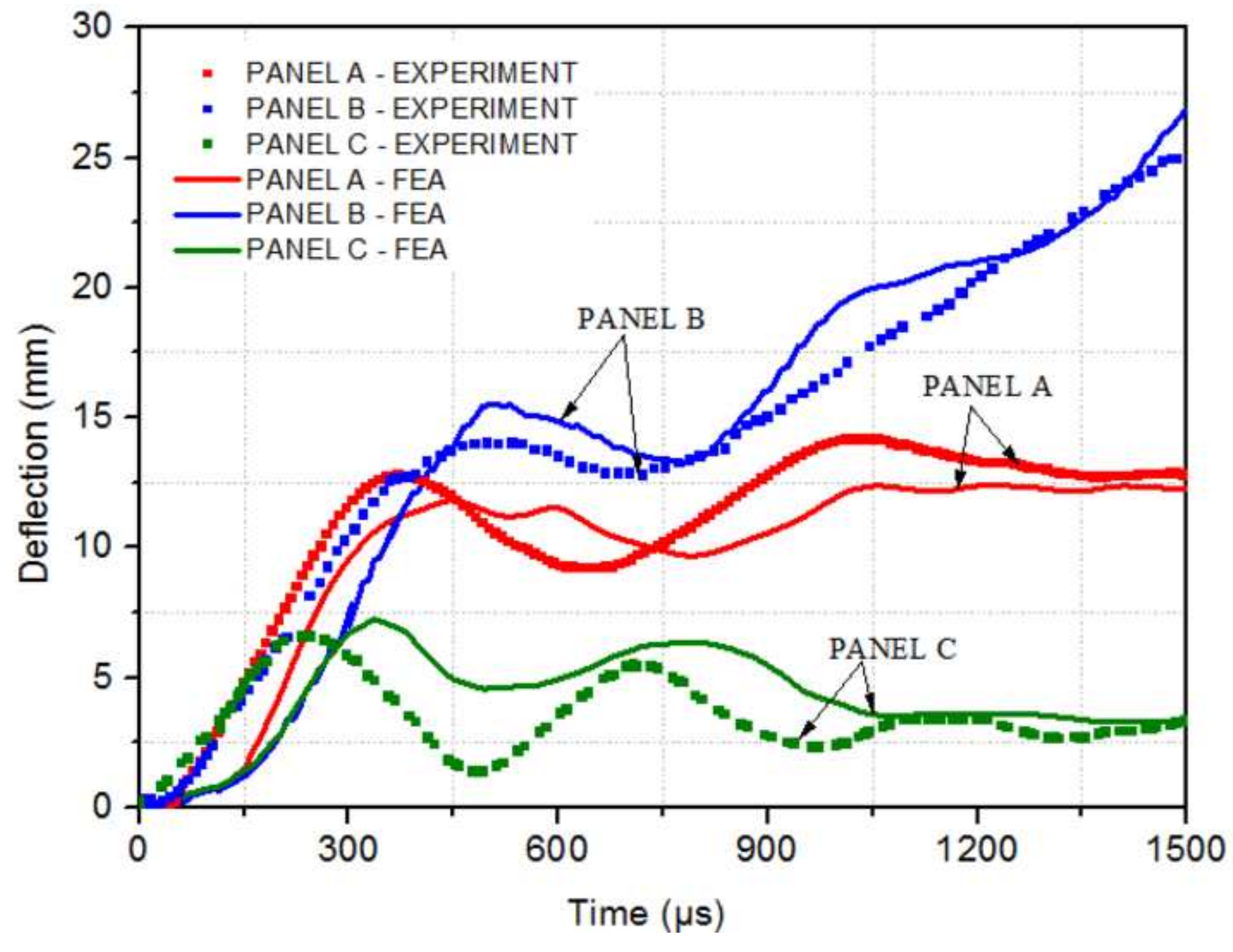




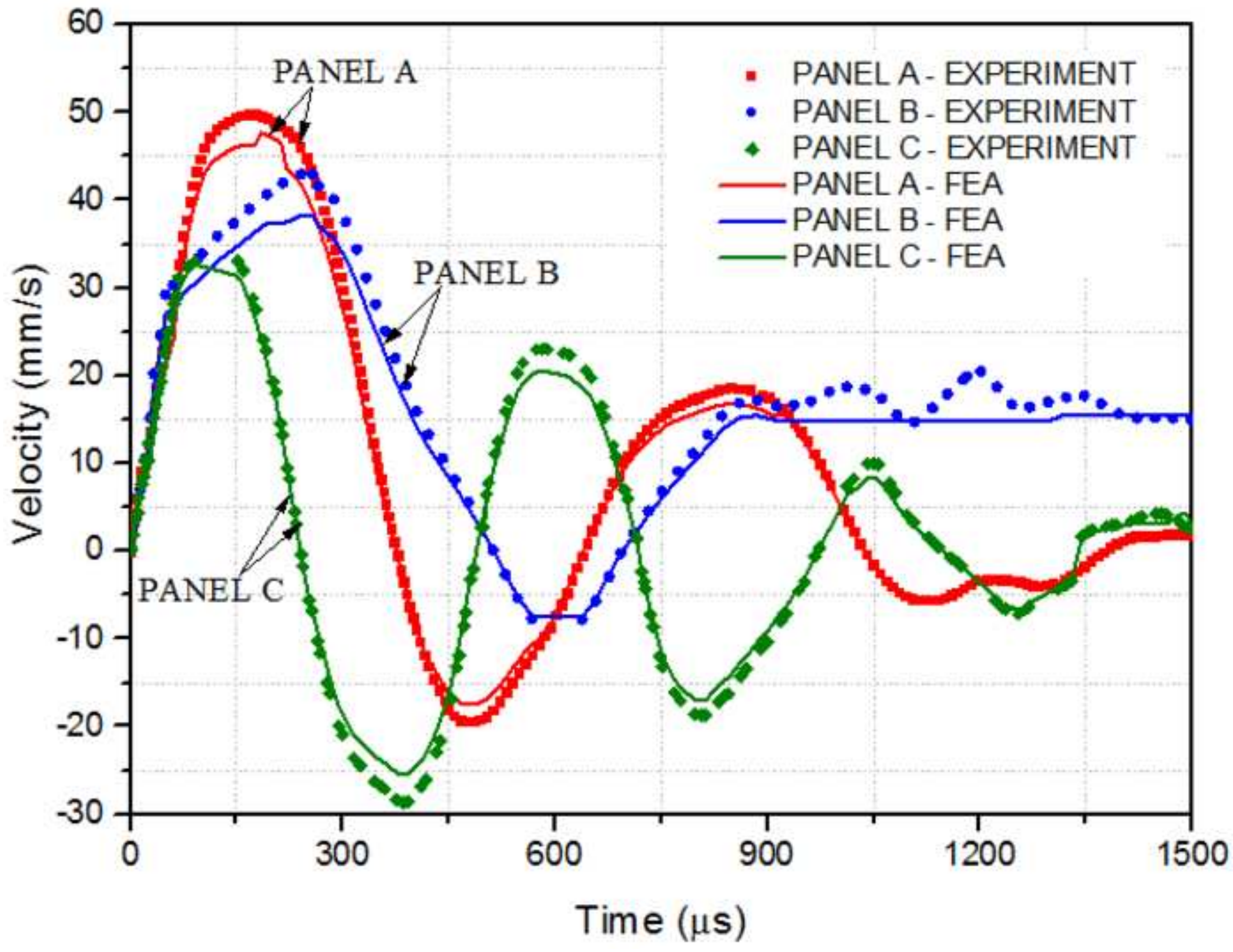




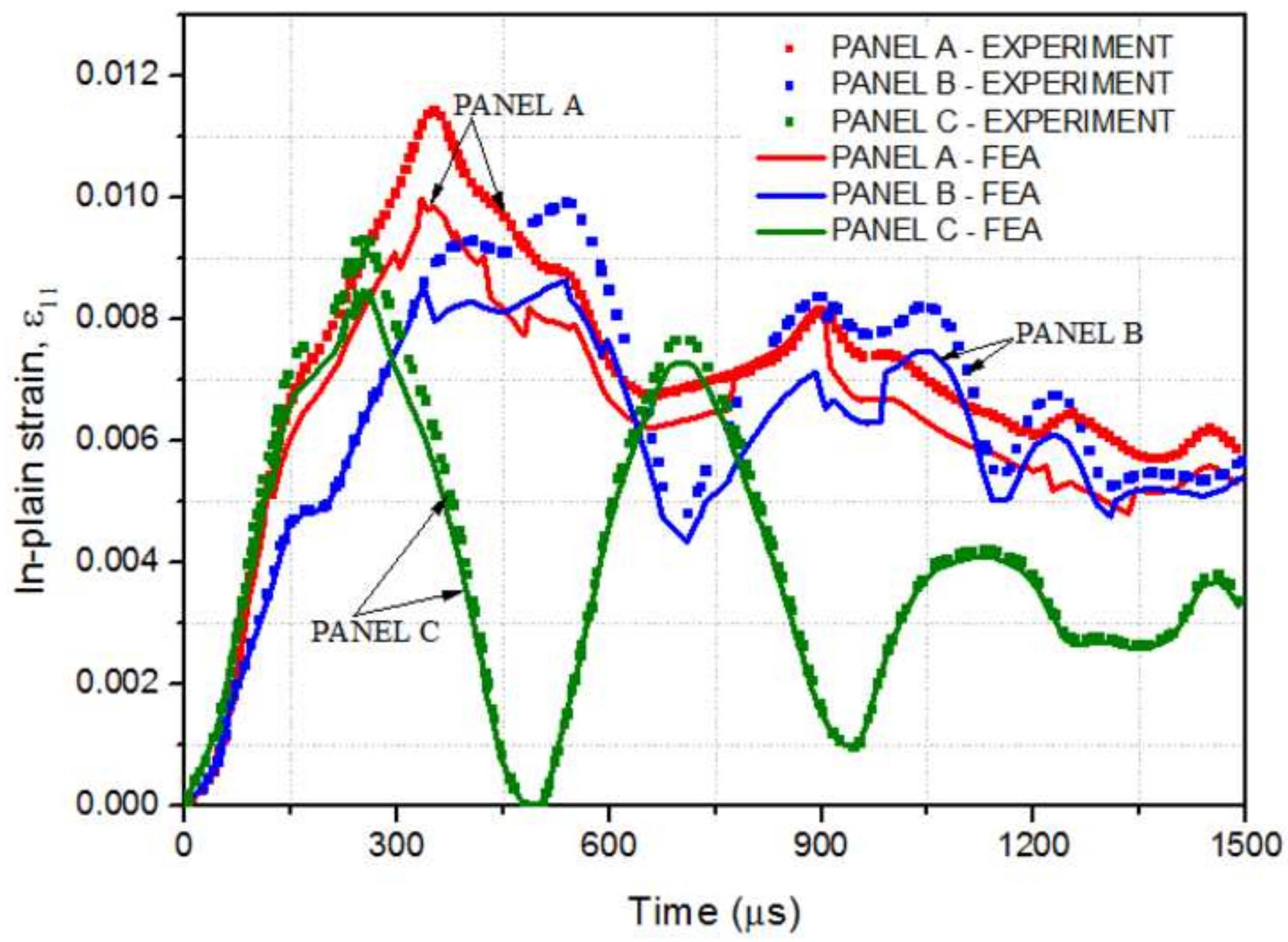


Figure 5

(a)
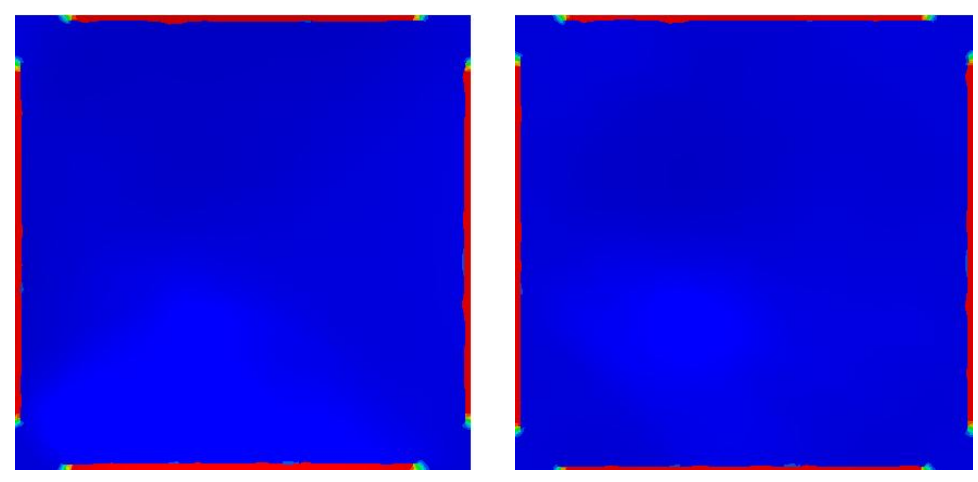

$400 \mu \mathrm{s}$
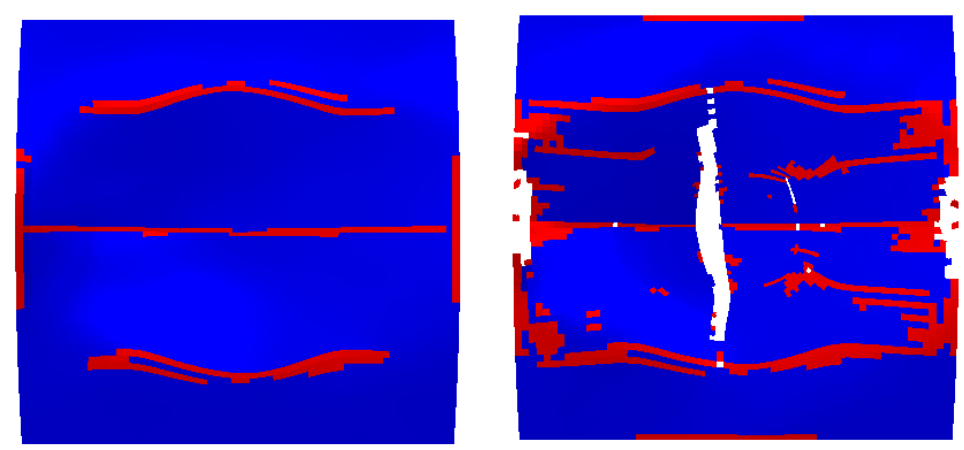

$800 \mu \mathrm{s}$

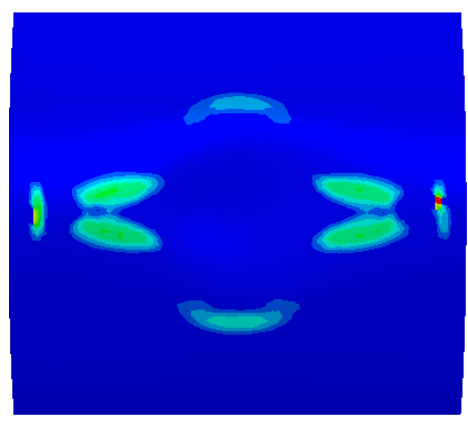

$800 \mu \mathrm{s}$

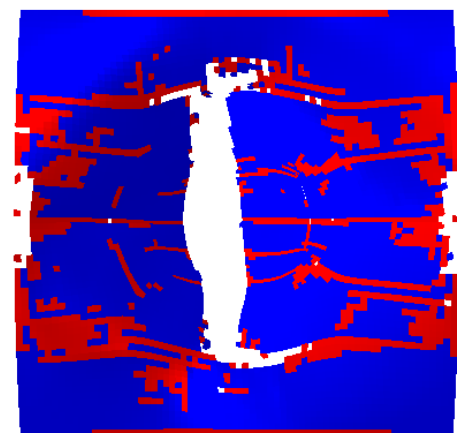

$1200 \mu \mathrm{s}$

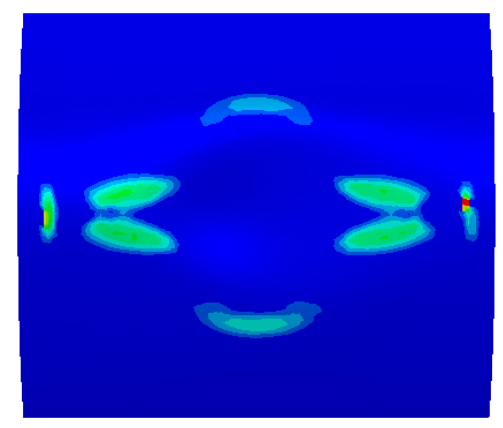

$1200 \mu \mathrm{s}$ 
Click here to download high resolution image

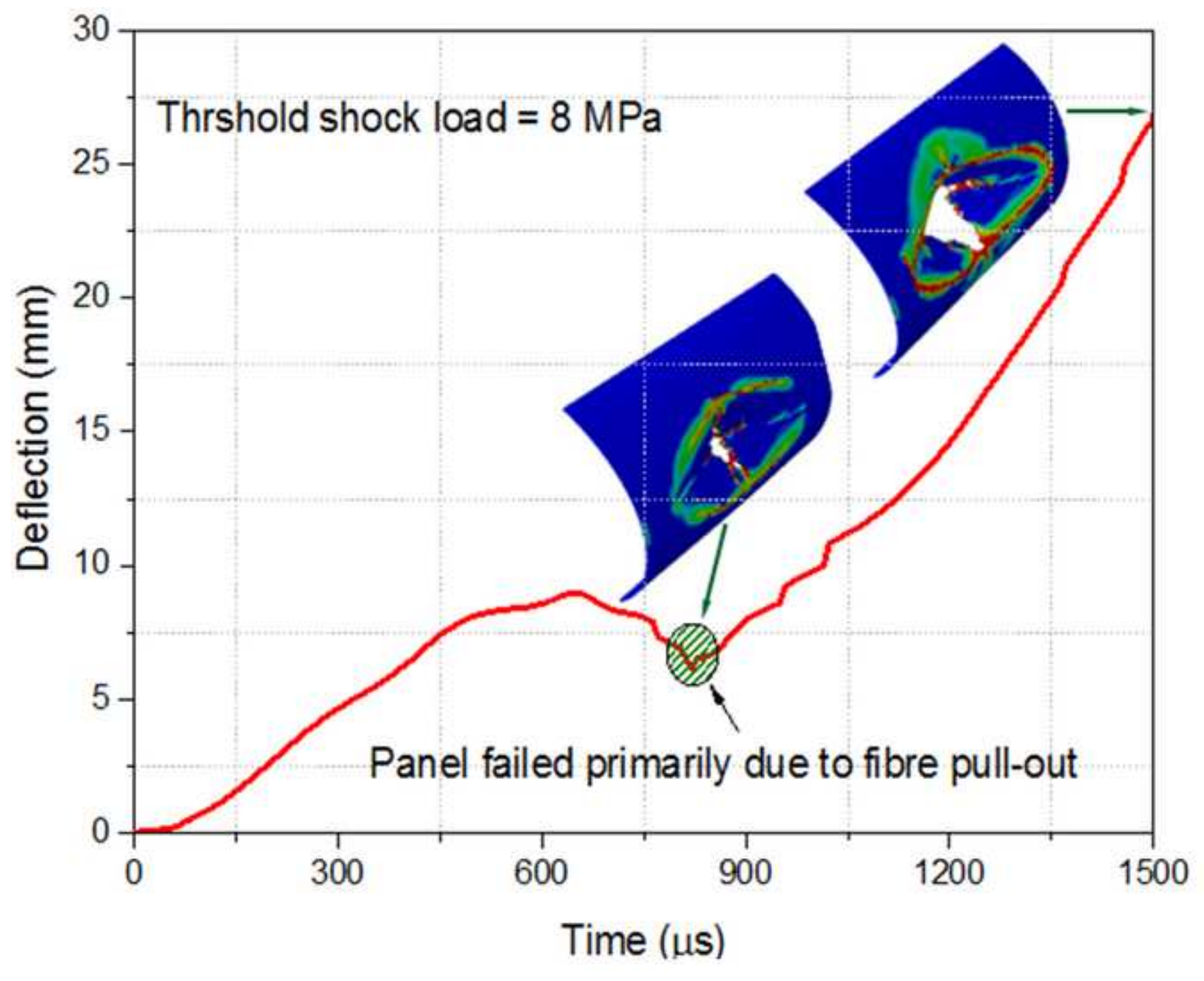




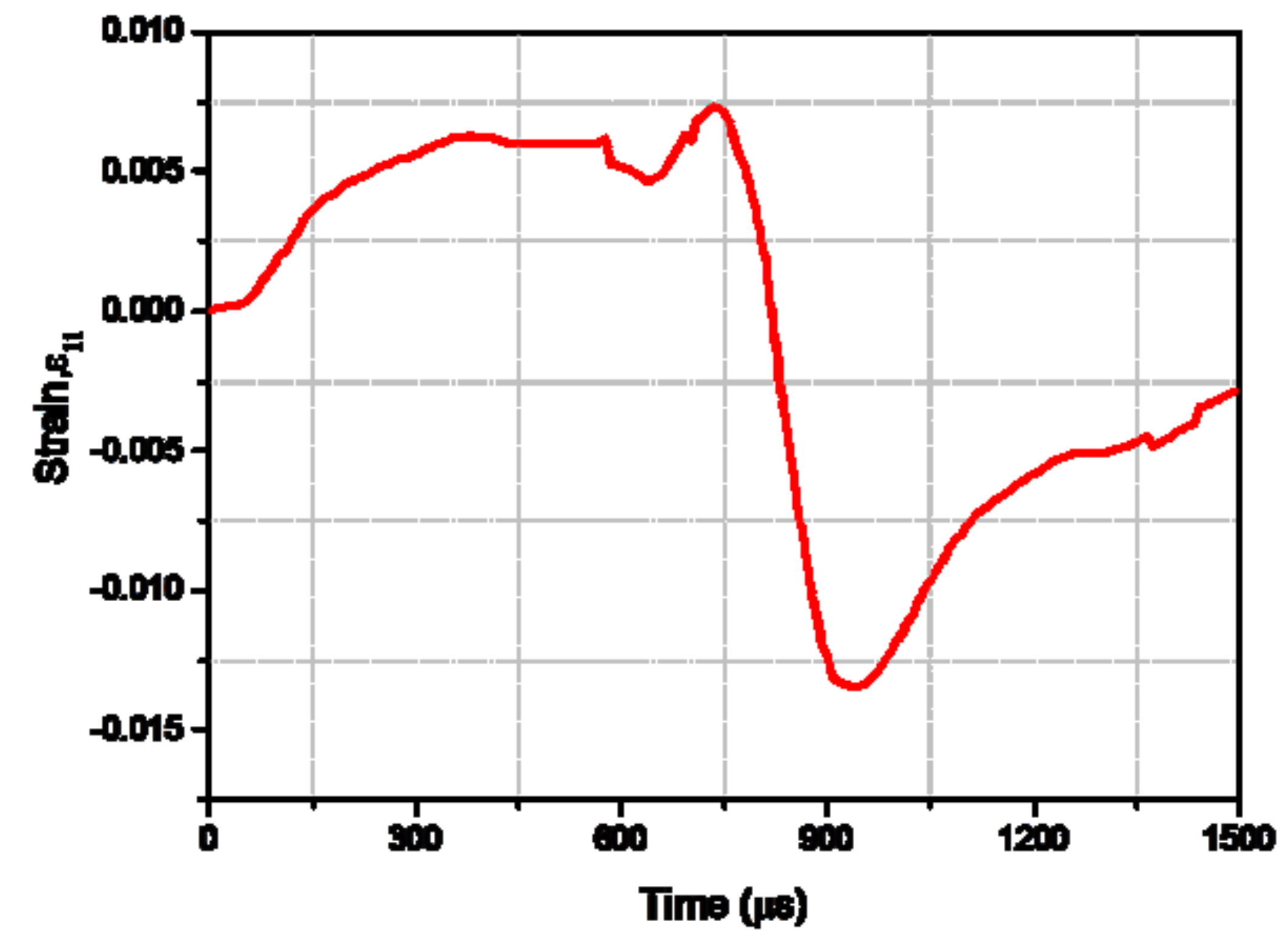

\section{Click here to download high resolution image}

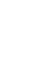




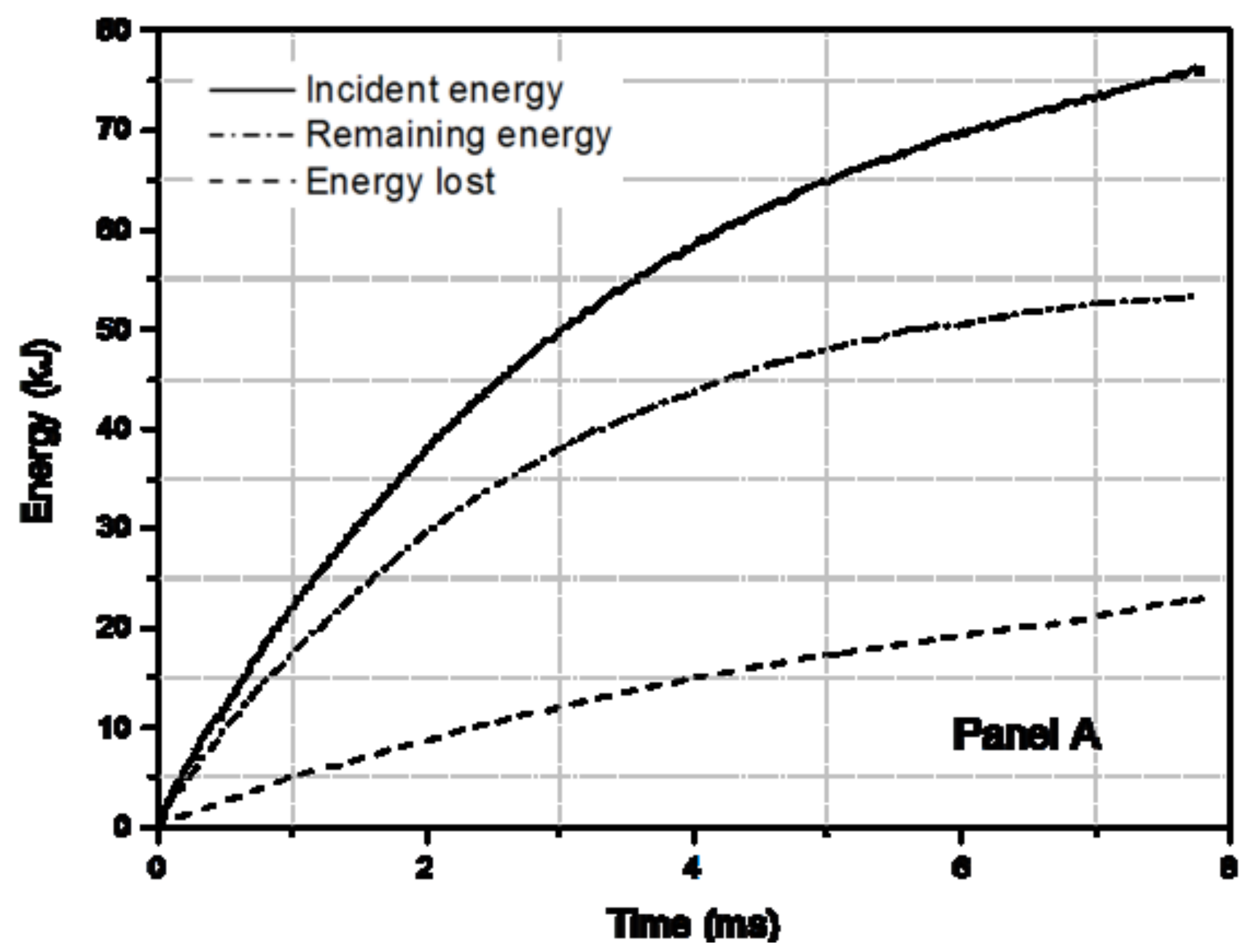




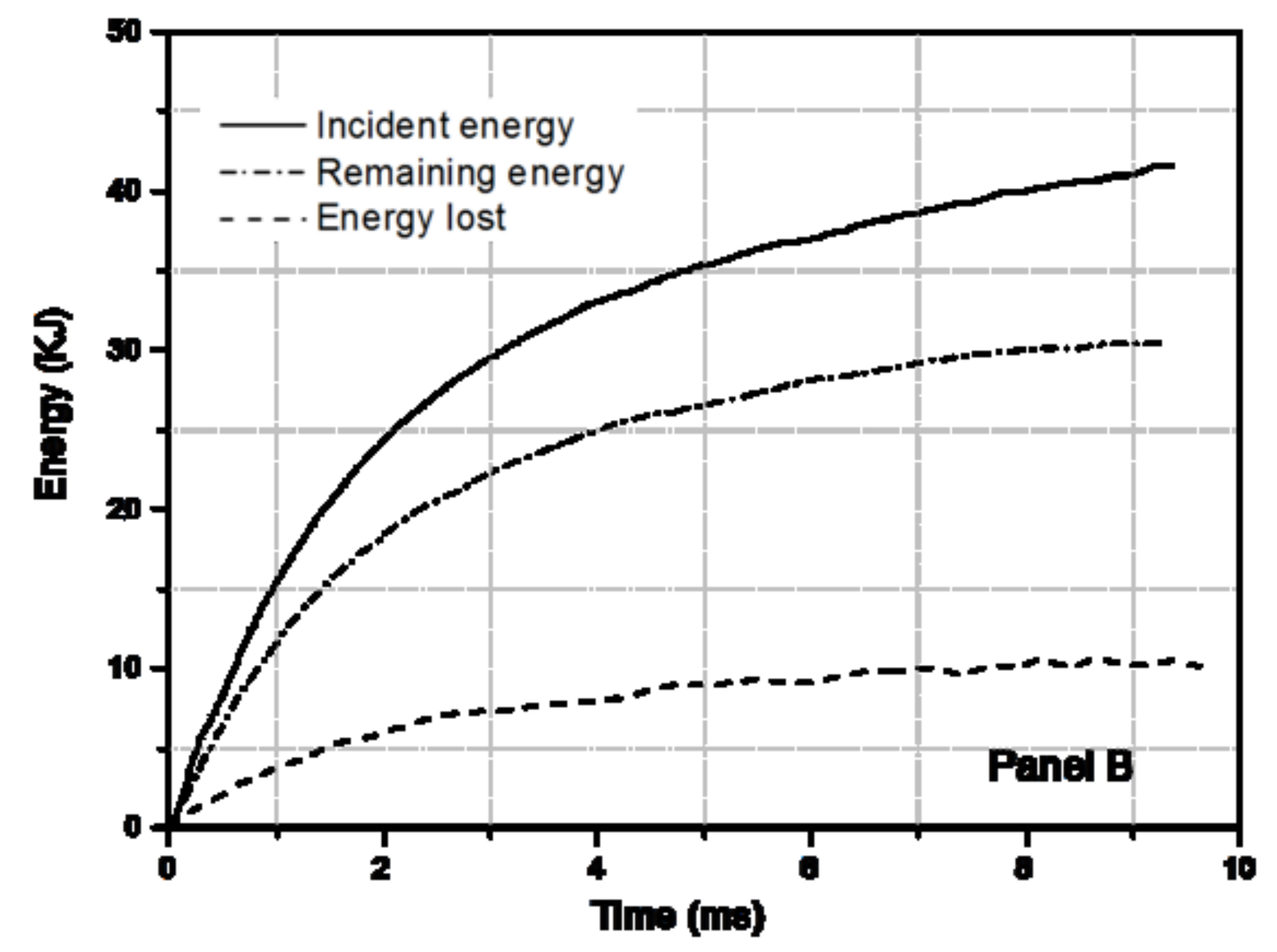

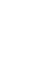




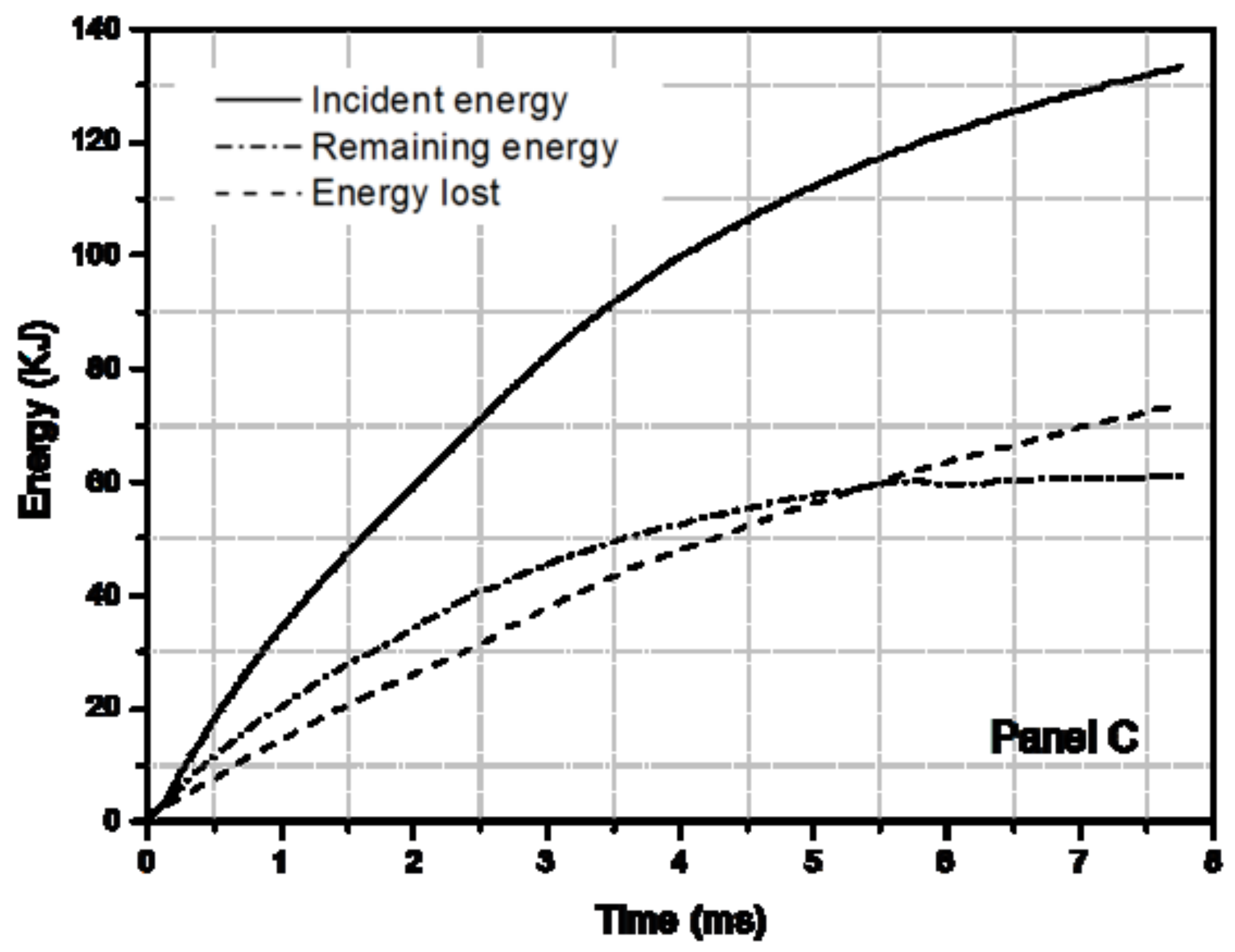

